\title{
Novas ações: Como as agências humanitárias ajudam no combate da vulnerabilidade e na atenuação dos fatores de risco
}

\author{
Felippe De Rosa ${ }^{1}$
}

\section{Resumo}

A discussão da amplitude da ajuda humanitária está em voga nos centros de estudo e pesquisa na área de relações internacionais. A capacidade e legitimidade da operação a longo prazo das organizações que provém esse tipo de operação está sendo questionada. Esse debate gira em torno da noção de que existem fatores de risco determinados de cada cidade, e cada ambiente dentro dessa cidade - seja zona rica ou zona pobre - tem uma vulnerabilidade distinta em relação à violência. Existe uma relação entre os fatores da pobreza, vulnerabilidade e violência, que se co-constituem, sendo os dois primeiros fundamentais para a estruturação do último. O argumento deste artigo busca corroborar com uma ação humanitária de caráter não somente de alívio, mas de forma mais ampla, aumentando a resiliência das populações locais, agindo de acordo com o imperativo humanitário que é invocado de igual maneira nesta conjuntura. Essa forma de ação não visa substituir as funções estatais ou operar dentro do vácuo de poder, mas serve como uma espécie de terceiro polo com funções de consultor. Sendo assim, as agências humanitárias vão trabalhar com o Estado nos assuntos que tangem as questões de proteção do Direito Humanitário Internacional, operando na forma de ações que provenham meios pelos quais os indivíduos possam sair da lógica ditada pela estrutura violenta e reintegrem essa cidade em um novo âmbito. O objetivo da ação dessas agências é a interferência no ciclo vicioso de pobreza, vulnerabilidade e violência para fortalecer a população local. Desta forma, é importante analisar se organizações humanitárias são capazes de contribuir no combate a vulnerabilidade e na atenuação dos fatores de risco. É por meio do reconhecimento dessas novas características do ambiente urbano que será possível intervir de modo a oferecer resiliência a população e melhorar as condições locais. Para melhor compreender a aplicação dessa nova estratégia de análise, será feito um breve estudo de caso sobre a realidade do conflito no Norte do México e a ação que Delegação Regional da Cruz Vermelha está realizando.

\section{Palavras-chave}

Vulnerabilidade, Fatores de Risco, Violência Urbana, México, Delegação Regional da Cruz Vermelha.

\footnotetext{
${ }^{1}$ Felippe De Rosa é graduando em Relações Internacionais pela PUC-Rio
} 


\section{Intrrodução}

A ação da ajuda humanitária tem mudado consideravelmente desde o final da Guerra Fria. As organizações que trabalham com esse tipo de operação tiveram a compreensão de que o desenvolvimento da sociedade alvo é fundamental dentro da consolidação da ajuda humanitária e que a conjuntura dos conflitos internacionais necessita de medidas mais amplas que abarquem essas características próprias dos locais. A noção de que a ajuda humanitária vai além do alívio humanitário imediato e serve, na verdade, como instrumento de resistência, entendido como resiliência, para as populações que sofrem com a violência local (Duijsens, 2010).

É nesse ponto, entre o alívio humanitário imediato e operações de longo prazo, que as opiniões se dividem e um novo campo de discussão e estudo se abre. Mediante a urgência da ação sobre áreas devastadas por conflitos, não existe discussão sobre a duração e amplitude do auxílio. O debate, todavia, encontra-se na situação em que o Estado ainda existe formalmente, em maior ou menor nível, mas não consegue prover as necessidades básicas em determinadas áreas. Em larga escala, essas áreas são marginalizadas e relegadas a lutas de facções e gangues pelo controle de um poder paralelo que se sobrepõe ao Estado. A discussão instaura-se sobre até que ponto é função da ajuda humanitária prover auxílio de longo prazo a essas localidades para que essas pessoas tenham meios auxiliares para criar uma espécie de "resistência” à situação local (Bangerter, 2010; Harroff-Tavel, 2010; Duijsens, 2010).

Portanto, antes mesmo de se aprofundar em tal debate, é fundamental compreender como surge a questão do combate a essa vulnerabilidade local imersa dentro de um contexto de violência urbana, observando como esse contexto vulnerável afeta as populações residentes. A ideia dessa análise é de que as localidades inseridas nesse contexto apresentam desafios em relação à capacidade e função do que pode ser feito pelo Estado, agências humanitárias e organismos multilaterais mediante essa estrutura. Outros problemas causados pela crescente urbanização edificam um cenário onde a cidade não consegue absorver e processar na mesma velocidade os fluxos de informação, pessoas e capital (Harroff-Tavel, 2010). Uma vez que um indivíduo reside nesse ambiente e este, por sua vez, não consegue oferecer as condições básicas esperadas, a situação agrava-se a partir do surgimento de uma massa de pessoas à 
margem da sociedade, entregues a vias de subsistências não legais e à pobreza (Carillo, 2009).

As cidades apresentam-se, então, como ambientes duais. Ao mesmo tempo em que oferecem uma oportunidade econômica e poder financeiro, sendo um porto seguro tanto para aqueles que estão retornando ao seu país - no caso de migração ou deslocamento interno - ou saindo do campo para tentar uma nova oportunidade nesse ambiente (Carillo, 2009; Duijsens, 2010; Harrof-Tavel,, 2010). Porém, dada a intensidade dos processos, nem sempre é possível que as cidades absorvam essa quantidade de fluxos, fazendo com que esses indivíduos entrem em um ciclo de pobreza, vulnerabilidade e violência (Carillo, 2009).

O resultado dessa conjuntura é o aumento exacerbado da violência dentro destes ambientes. A análise da estruturação da violência e seu combate precisam de uma abordagem que não só entenda os sintomas do fenômeno - sejam eles o aumento da criminalidade, a fuga de investimentos de capital público ou privado ou os problemas legais que decorrem dos atos criminosos -, mas também quais são as interações responsáveis pelo aumento dessa violência e medidas para o combate a essa situação.A concepção de riscos e vulnerabilidade é primaz para conceber esse pensamento (Agostini, Chianese, et al., 2007).

Antes de a situação chegar necessariamente à violência existe uma conformação de fatores de risco que são agregados à localidade que estruturam esse resultado, sendolhes particulares. São resultados de processos históricos próprios a cada localidade. Cada situação apresenta seus fatores de risco próprios e que interagem em uma relação específica em cada cidade. Essa relação e interação se dão a partir do conceito de “vulnerabilidade”, que vem aliado à concepção do "risco”. A vulnerabilidade pode ser compreendida como sendo uma maior fragilidade no sentido de que um risco se concretize. A vulnerabilidade então aparece como uma condição de possibilidade na qual os riscos podem encontrar espaço para agir. É por meio de uma conjunção de risco e vulnerabilidade que podemos chegar a um correto entendimento de onde começa a violência a se estruturar e quais são os fatores que a catalisam (Agostini, Chianese, et al., 2007; Bangerter, 2010).

Sendo assim, os fatores de risco de uma determinada localidade em conjunção com um momento econômico desfavorável em uma localidade vulnerável - por 
quaisquer motivos que sejam: rápida urbanização, acesso desigual aos meios econômicos, falta de oportunidade, condições de subsistência precárias - podem fazer desencadear um processo de hostilidade com violência naquele local. Logo, a cada análise de uma conjuntura é necessário analisar quais são os riscos que lhe são próprios e a sua vulnerabilidade para lidar com eles. Essa situação não é um fenômeno isolado, mas é resultado da construção de uma relação entre esses dois conceitos (Agostini, Chianese, et al., 2007).

Desta forma, o presente artigo tem como finalidade analisar a importância da concepção de fatores de risco e vulnerabilidade para o combate a violência no ambiente urbano. Sendo assim, primeiramente abordarei a questão de como a percepção de fatores de risco e vulnerabilidade dentro da cidade são fundamentos importantes para a compreensão mais abrangente e completa de combate à violência. A redução da violência nesse contexto só será possível a partir da estruturação de uma política pública que leve em consideração a constituição deste fenômeno como um todo, e não somente sua fase final. É uma compreensão mais ampla no sentido de que não é só uma ação pontual de combate, mas um olhar sociopolítico sobre a reestruturação da sociedade, a fim de lhe prover resistência, concebida como resiliência local, para desarticular o ciclo de vulnerabilidade, pobreza e violência.

\section{Novas formas de análise}

Para compreender a importância dessa nova forma de análise dentro da consideração das formas como uma população é afetada pela violência, isto é, a análise dos fatores de risco e da vulnerabilidade local, é preciso primeiro entender a violência como um processo estrutural que se edifica. Não é uma simples característica fixa, $e x-$ ante ao processo de formação urbana da sociedade, mas é construída a partir da confecção de fatores históricos e políticos específicos. Tendo uma condição estrutural, podemos perceber que sua manifestação também não ocorre de uma só forma, podendo ser uma violência de caráter social, econômico e político (Moser \& Mcilwaine apud Agostini, Chianese, et al., 2007). Essa percepção de uma violência multifacetada reflete a complexidade da resposta de violência urbana, necessitando uma ação em múltiplas áreas (Agostini, Chianese, et al., 2007; Harroff-Tavel, 2010) 
Com diversas formas de manifestação, a violência afeta as sociedades urbanas de maneiras cada vez mais invasivas. Esse processo urbano acelerado é uma das causas que exacerbam a lógica caótica de exclusão, no qual a cidade, bem como a política pública do Estado, não consegue absorver o fluxo de informações, mudanças e pessoas que invadem a cidade com essas mudanças. O processo de marginalização tem origem mediante o "excesso" entre esses fluxos e o que o Estado consegue absorver e acaba por insular uma parcela da população, que se vê relegada a recorrer a vias não estatais. (Harroff-Tavel, 2010). Podemos cada vez mais entender a exclusão da parcela que usufrui das funções, ainda que não plenas, do Estado como uma das causas estruturais da violência (Carillo, 2009).

Não é somente pelo processo de exclusão que a violência se estrutura, tendo a capacidade de absorção desses atritos e impactos de cada cidade uma grande importância. A diversidade da constituição histórica e geopolítica das cidades afeta esse impacto. De fato, o processo de urbanização acelerada não pode ter os mesmo efeitos ao mesmo tempo em todas as localidades por causa das diferentes estruturas que as cidades apresentam. É nesse ponto que é importante analisar como a vulnerabilidade de cada cidade afeta os fatores de risco das localidades de forma distinta (Agostini, Chianese, et al., 2007).

Uma vez que a violência se estrutura a partir de um processo que leva em consideração fatores como a percepção de um ambiente vulnerável propenso a riscos da localidade, o seu combate não pode ser restrito às camadas mais superficiais da questão. O ambiente urbano parece precisar de um acompanhamento de longo prazo no que tange o trato com os sintomas e causas da violência.

O trabalho de Giulia Agostini, Francesca Chianese, William French e Amita Sandhu (2007), autores do relatório da London School of Economics Understanding the Process of Urban Violence, discorre sobre como as cidades sempre representaram um lugar de abrigo e acolhimento. O ideacional do indivíduo quando imagina uma cidade está apropriado a esses termos. Entretanto, o relatório aponta que nos anos recentes, dado o aumento da vulnerabilidade das cidades à guerras e conflitos, essa visão tem mudado. Desde o início do seu texto existe o direcionamento da atenção para o caráter vulnerável da cidade como preceptor da condição de violência (Agostini, Chianese, et al., 2007). 
A disputa na cidade, dado o seu ambiente de luta inserido na competição pela subsistência, é considerada um fator importante para o caráter vulnerável da cidade. Tendo em vista essa característica, Agostini et al afirmam que os riscos e sua interação em um ambiente vulnerável precedem a violência. A partir dessa constatação demonstra-se como essa interação irá produzir resultados violentos em uma conjuntura contextual. Existe, portanto, a necessidade de formular uma política para a observação e análise conjuntural dos processos de violência urbana por meio de estudos de caso que se embasam nessa ressalva de análise de riscos e vulnerabilidades (Agostini, Chianese, et al., 2007; Duijsens, 2010).

Através de estudos de caso percebe-se a existência de diversos tipos de fatores de risco que são importantes para a estruturação da violência. Os fatores seriam divididos em três e a produção de um resultado violento dá-se pela sua interação e atrito, aliada à permissividade do contexto vulnerável. Existiriam os fatores de nexo primário, que traduzem um alinhamento comum entre todos os casos estudados pelo autor. Tendo como pano de fundo os casos de Kinshasa, Nairobi e Bogotá. Os fatores primários seriam: a crise de governança, tendo o aparato estatal algum tipo de falha e/ou relação com os problemas dentro do país, o que contribui para a desconfiança nos seus mecanismos; acesso desigual à oportunidade econômica, por meio do monopólio das oportunidades pelas elites, relegando os menos providos à procura de formas ilegais de subsistência; declínio econômico, caracterizado por crises econômicas nos países; e a naturalização do medo e da insegurança, tendo o processo de violência um caráter rotineiro e perpétuo (Agostini, Chianese, et al., 2007).

O exercício dos autores é fundamental para o entendimento de como os fatores de risco em sua interação, adicionado ao caráter vulnerável das localidades, acabam por resultar em um caminho que leva a violência. A violência, portanto, não surge apenas da pauperização ou exclusão, não é um fenômeno que ocorre apenas por um fator isolado, mas por uma conjunção de fatores, que mediante a uma relação entre si e com a localidade resultam na violência. Ela é um processo construído e não característica de um lugar. A necessidade de que os estudos de conflitos tenham avaliações embasadas no estudo entre riscos e vulnerabilidades permite que se possa compreender como a 
violência se estrutura em um determinado local ${ }^{2}$.

Nessa concepção do que são os fatores de risco e como eles estão propensos e condicionados a absorção ou permissividade da vulnerabilidade é que a análise de um “como” desestruturar essa relação de violência faz-se necessária. Existem novos desafios que o ambiente urbano apresenta para a ação desse combate a violência ${ }^{3}$, e é ao analisar o urbano como um novo desafio ao humanitarismo que podemos ver a convergência de como o contexto de vulnerabilidade e o ambiente da constante falta nas margens podem ser um ponto de catálise da violência (Harroff-Tavel, 2010).

A questão relacional da vulnerabilidade dos locais dentro da cidade e a pobreza apareceriam como fator preponderante. Os lugares com melhores condições econômicas estão mais bem providos e menos vulneráveis do que os lugares menos providos Os riscos de uma tragédia - podendo ser ela até de caráter natural - acontecer é praticamente o mesmo, dado que estão inseridos em uma mesma localidade. Todavia, os lugares mais pobres estão mais vulneráveis aos efeitos dos desastres. Em relação às tragédias naturais, por exemplo, as condições de moradia, de infraestrutura e de alcance do aparato estatal são deficitárias, tendo seu alcance restrito e dificilmente atingindo essas áreas.. Em relação à violência, podemos fazer a mesma analogia, onde os riscos se distribuem da mesma forma, mas os lugares mais pobres dentro da cidade são mais suscetíveis nessa questão graças a sua maior vulnerabilidade, podendo esta ser tanto física, econômica, como política (Agostini, Chianese, et al., 2007; Duijsens, 2010).

Ao afirmar que existe um processo de retroalimentação entra a vulnerabilidade das localidades, a pobreza e a violência, existe o reforço que a noção de que apesar dos fatores de risco estarem presentes, eles só se concretizam a partir de um ambiente propício que venha a existir. O desafio para as agências humanitárias reside, em grande medida, na questão da crise permanente que provém desse ciclo: a constante falta ${ }^{4}$ que

\footnotetext{
1 Para fazer referência sobre este argumento observar o trabalho de Mitchell J K. 2003. Urban Vulnerability. In: The Geographical Dimensions of Terrorism, Cutter S L, Richardson D B, Wilbanks T J. Routledge: New York and London: 17-25. Para outra análise semelhante ver o trabalho de Susan E. Clarke \& Erica Chenoweth. The Politics of Vulnerability: Constructing Local Performance Regimes for Homeland Security. Policy Research, Volume 23, Number 1, 2006

${ }^{2}$ Para ver entre o ambiente urbano e ambiente cidade vero trabalho de Marion Harroff-Tavel Violence and humanitarian action in urban areas: new challenges, new approaches. International Review of the Red Cross. Volume 92, Number 872, June 2010

${ }^{3}$ A noção de "falta” abordada no presente artigo tem sua fundamentação no trabalho de Angela Consuelo Carillo "Internal displacement in Colombia: humanitarian, economic and social consequences in urban settings and current challenges. “International Review of the Red Cross, v. 91, n. 875, p. 527-546,
} 
torna a situação crítica. A necessidade de lidar com esses desafios demanda às agências humanitárias o aumento da resiliência dos indivíduos, a fim de intervir nesse ciclo para diminuir ou acabar com a vulnerabilidade (Bangerter, 2010; Duijsens, 2010).

\section{Novas formas de resistência}

Compreendendo que a violência advém da relação da cidade com uma lógica de exclusão aliada a vulnerabilidade local e sua propensão aos fatores de risco, é que diversos autores apontam como fundamental o apelo à ajuda humanitária internacional, defendendo que ele pode ser evocado nessa situação. A participação proposta ao humanitarismo por essa nova realidade pode ser dentro da lógica de que o alívio do sofrimento vai oferecer um tipo resistência a essa condição do ambiente. É na percepção de uma resposta mais estruturada nesse tipo de relação que as agências podem suprir parte de falta inerente a essa localidade. Não seria ele a solução definitiva para a eliminação dos fatores de riscos dentro de cada localidade, mas parte de uma política de atenuação dessa vulnerabilidade e resistência aos riscos (Bangerter, 2010).

Para tanto, os estudos específicos de análise do ambiente urbano tomaram emprestado dos estudos de ecologia o conceito de resiliência. Esse conceito aparece como sendo fundamental na compreensão do possível trabalho das agências humanitárias dentro dos ambientes vulneráveis. Na ecologia, resiliência aparece como sendo a capacidade que um ambiente tem de retornar a situação anterior a um desastre ou alguma ação antropomórfica que provocou algum tipo de dano ao sistema. Sendo assim, a resiliência mostra-se como um fator de reestruturação e revitalização da estrutura por si só, sem a intervenção. É uma capacidade própria do ambiente, que aparece em maior ou menor grau dependendo das condições mais variadas dentro do sistema. O conceito da resiliência dentro dos estudos de violência urbana, por sua vez, aparece com as mesmas características, mas com um foco diferente daquele da ecologia. Resiliência, nesse sentido, aparece como a capacidade que a sociedade tem de atenuar aos fatores de risco e a vulnerabilidade local, também sendo uma característica

Setembro 2009. É a ausência não só de serviços e políticas do Estado diretamente direcionadas para a população, mas a "falta" de condições básicas que não marginalizem e excluam o indivíduo, podendo ser caracterizada como falta de educação, carência na área de saúde, falta de um mercado de emprego, ausência de centros comunitários dentre outros. A "constante falta” é um termo que a autora usa para afirmar que essas localidades estão constantemente marginalizadas e excluídas, dando uma noção mais abrangente do conceito. 
adquirida pela própria a comunidade por meio do seu desenvolvimento (URCV, 2011; Coaffee, 2006).

Assim, faz-se necessário o debate sobre essa capacidade enquanto um fenômeno social e não uma capacidade dada. Tendo uma sociedade seus fatores de risco próprios e as vulnerabilidades de seus ambientes, a noção de que alguma medida pode ser tomada para aliviar essa tensão é de extrema importância. Essa medida pode ser vista como sendo a atuação de uma medida da própria sociedade civil como ajuda no processo de aquisição e fortalecimento da localidade. O processo de aumento da resiliência social tem uma nova função enquanto uma ação que visa intervir nessa lógica de retroalimentação da pobreza e vulnerabilidades locais em um processo de reconstrução (Coaffee, 2006; URCV, 2011).

A noção de co-constituição desses dois fenômenos é um ponto central na análise da violência e em modos de suavizar seu impacto dentro das sociedades mais vulneráveis. A questão da vulnerabilidade e a pobreza aparecerem como ponto focal preponderante. Esse pensamento nos elucida que apesar de os fatores de risco estarem presentes, eles só se concretizam a partir de um ambiente propício que no caso existe. O desafio que afirma existir para as agências humanitárias reside, em grande medida, na questão da crise permanente que provém desse ciclo: a constante falta que torna a situação crítica (Carillo, 2009; Harroff-Tavel, 2010). É nessa nova necessidade mediante a crise constante que podemos ver um novo tipo de demanda às agências humanitárias, a de aumentar a resiliência dos indivíduos visando intervir nesse ciclo a fim de diminuir ou acabar com a vulnerabilidade (Agostini, Chianese, et al., 2007; Coaffee, 2006; URCV, 2011).

As demandas que esses ambientes vulneráveis acabam criando podem ser encaradas como uma nova dimensão dentro das ações das agências humanitárias. Conforme anteriormente dito, essa intervenção das agências humanitárias pode ser vista como uma interpretação diferenciada de como funcionaria sua atuação enquanto promotores de alívio para o indivíduo. A lógica do humanitarismo enquanto princípio de alívio do sofrimento não muda em sua essência, mas tem uma alteração no seu escopo de atuação.

A questão passa a ser então o modo de atuação das agências e o prazo para a atuação no ambiente de violência urbana local, trazendo um novo aspecto para a 
discussão. O período de ação da ajuda humanitária gera controvérsias dentro da comunidade que discute as práticas aplicadas à realidade do conflito (Barakat, Dely e Zyck, 2010). O consenso sobre como deve funcionar essa aferição do tempo necessário para que o "sofrimento seja aliviado" não existe de fato, havendo apenas diversos grupos dentro dos debates que defendem diversas opiniões ${ }^{5}$ (Bangerter, 2010).

A questão geralmente circula mais em torno da capacidade de ação de uma agência humanitária a longo prazo, isto é, da duração de tempo que a operação deve ter, do que a própria necessidade de uma ação (Ibid). Existe um grande receio sobre como essa ação pode minar o controle estatal na região e ajudar na formação de um poder paralelo local. O argumento que se levanta contra a possibilidade dessa ação mais extensa no sentido temporal tem como principal ponto a responsabilização do Estado como ente primário para a composição do corpo básico de serviços para a sua população local, não cabendo a ação humanitária essa ação em larga escala ${ }^{6}$. Além disso, questiona-se a capacidade das agências de se sustentar na localidade com suas capacidades físicas, técnicas e financeiras, consideravelmente menores que a capacidade estatal. Portanto, é importante notar que surgem duas questões distintas no processo.

A primeira delas é quanto à responsabilidade, ou seja, quem é o responsável pela a agência dentro dessa realidade. Existe uma visão de que o Estado é aquele quem tem a legitimidade e a responsabilidade da ação, sendo defendida no modo de que o controle dessa ação. Seria um controle de caráter político, no qual a função do Estado é suprir essas populações. Caberia então ao Estado realizar esse processo de resiliência junto a essas populações e não às agências humanitárias. Seria uma invasão a própria noção soberana da agência política do Estado que haja um tipo de suporte paralelo que não seja o seu. É importante frisar que a situação de violência urbana que propõe esse tipo de discussão de vulnerabilidade não é a mesma que um conflito generalizado onde o Estado não tem mais nenhuma capacidade. Aqui, o Estado tem controle sobre grande parte de seu território e sua ação soberana. O fenômeno da vulnerabilidade e dos fatores

\footnotetext{
${ }^{5}$ O debate da aproximação da ajuda humanitária do estado e a sua repercussão nas práticas humanitárias são abordadas por BARAKAT, S.; DELY, S.; ZYCK, S. A. perspective., 'A tradition of forgetting': stabilisation and humanitarian action in historical perspective. Overseas Development Institute, 2010. Ver página 3.

6 Não é objetivo de o artigo debater as diferenças entre alívio humanitário e políticas desenvolvimentistas. Para mais informações sobre esse aspecto, ver a obra de WEISS, T. G. Humanitarian Intervention. Cap . 2 "Humanitarian" interventions: Thumbnail Sketches. Londres: Cambridge, 2007, p. 196
} 
de risco são analisados no contexto de ambiente específico que sofre de violência urbana e não um conflito generalizado em todo o país, onde a ação humanitária é legítima (Agostini, Chianese, et al., 2007; Bangerter, 2010).

Esse pensamento, entretanto, apresenta um problema quanto à percepção de controle irrestrito e parcial do território. Os ambientes em que as necessidades humanitárias são demandadas - tendo em vista o desafio da violência urbana - podem ser compreendidos como dentro da lacuna da ação Estatal. Isto não quer dizer que não existe o esforço ou a tentativa de controle por sua parte, mas que quando os fatores de riscos foram se estruturando e a vulnerabilidade se edificando em torno dele, o Estado não estava presente para frear esse processo. Nesses casos, não houve política pública efetiva de intervenção sobre os fatores de risco e da vulnerabilidade local em sua formação (Duijsens, 2010; Bangerter, 2010).

Nesses casos, a ação humanitária apresenta-se como uma alternativa no processo de estruturação de resiliência nessas comunidades que procura minar o ciclo vicioso estruturador dessa situação de violência (Duijsens, 2010). Uma política de longo prazo liderada por uma agência humanitária poderia intervir, sendo um novo polo para a mediação entre as partes desse conflito gerador da violência urbana e o Estado. Para tanto, é só mediante a uma ação de caráter mais estrutural que paliativo que as agências humanitárias podem entrar como desarticuladores desse ciclo vicioso. A ação para a quebra desse ciclo aparece como sendo uma nova função que as agências humanitárias devem fazer em meios violentos (Bangerter, 2010).

Atentando para um caráter de neutralidade fundamental, a ação humanitária serve a um duplo propósito. Primeiramente, com função natural da missão humanitária, ela visa interferir para o alívio do sofrimento da população vulnerável, de modo que com isso também acabe contribuindo com a construção do processo de resiliência local. Isso se dá pela contribuição estrutural à localidade, suprindo a necessidade de um conjunto de medidas que inserem a comunidade em um ambiente vulnerável. A prática dessa ação será analisada a seguir, mas cabe adiantar que é pela ação efetiva na localidade como um pólo adicional na relação binomial entre Estado e comunidade, que a ação humanitária funciona como um importante meio de prover resiliência à população.

O segundo propósito advém desse posicionamento como pólo neutro e exterior à relação, que serve de ente imparcial para uma a reaproximação e reinserção do Estado 
nessa localidade excluída. Esse ponto de ação das agências humanitárias aparece como fundamental para afirmar e garantir que as medidas práticas na localidade tenham um caráter mais efetivo de intervenção no ciclo da pobreza, vulnerabilidade e violência. A reaproximação do Estado garante que as medidas empreendidas pelas agências sirvam não só como um auxílio passageiro, mas de modo a ser uma nova força para tirar a população local da vulnerabilidade. O acompanhamento das operações, bem como a assinatura dos tratados de garantias dos direitos humanos, a exemplo do caso proposto, convergem para uma maior atenção do Estado às comunidades vulneráveis. As agências humanitárias servem, portanto, como uma espécie de consultoria, indicando as lacunas em que a necessidade de atenção é fundamental. Essa forma de ação não visa substituir as funções estatais ou operar dentro do vácuo de poder, mas foca em prover auxílio específico na área de preservação aos direitos humanos internacionais, como uma forma de reintegrar essa cidade.

Outro ponto que aparece dentro dessa discussão de uma intervenção humanitária que não foque somente no alívio e sim em uma ação que vise desestruturar o ciclo vicioso da vulnerabilidade, pobreza e violência é a questão da capacidade das agências de lidar com essa situação. Diferente de uma ajuda pontual que foca no alívio imediato das populações que são alvos de conflitos armados, esse tipo de ação iria requerer um novo foco e o empreendimento de esforços consideravelmente maiores (Ibid). A discussão repercute em torno de quais agências estariam dispostas a fazer esse tipo de operação e como ela seria realizada (Agostini, Chianese, et al., 2007).

Apesar de a questão ser complicada e, mais uma vez, aparecer a temática de a quem pertence essa responsabilidade, o pensamento desenvolvido no presente artigo tenta corroborar com a possibilidade das agências humanitárias empreenderem esses esforços. Entretanto, o tipo de organização que seria capaz de realizar esse empreendimento é que apresentaria algum tipo de restrição. Só organizações de grande porte, como o Comitê Internacional da Cruz Vermelha, é que seriam capazes de realizar e redirecionar os esforços necessários em prol dessa nova função. Ela não seria a única com capacidade, mas é a que, por sua ampla atuação, captação de recursos e tradição, tem as melhores capacidades financeiras, técnicas e, principalmente, com uma abrangência significativa sobre essas áreas, o que a tornaria suficientemente capaz de fazer essas ações (Bangerter, 2010). 
A questão da capacidade e aptidão da Cruz Vermelha tange alguns pontos. Primeiramente, o Comitê Internacional da Cruz Vermelha tem uma rede de voluntários bastante ampla, o que possibilita maior interação e contato com diversos tipos de público alvo - no caso mexicano, com os cartéis. Não obstante, no que tange o material humano da organização, a qualificação desse pessoal em diversas áreas, tais como direito, sociologia, especialistas em segurança, engenharia sanitária e saúde, permitem que exista uma maior contribuição para os projetos da região, também sendo crucial o fato de que, por definição, exista uma representação nacional, o que facilita a comunicação na língua local. Em segundo lugar, a existência de um escritório local da Cruz Vermelha nas localidades contribui para o critério da duração do programa, não sendo afetados por redirecionamentos de agenda, além de ser um fator que contribui para a coerência na atuação, sendo um escritório que coordena as ações em escala nacional (Bangerter, 2010).

Além dessa questão, a discussão não pode enveredar somente pela capacidade material, mas também pela própria questão ideacional apresentada por esse novo processo. A situação não é uma calamidade de conflito ou desastre deflagrado que necessita de um alívio imediato. É uma medida que visa o estabelecimento de um relacionamento maior com a localidade, a fim de interferir no processo de construção do ciclo vicioso da pobreza, vulnerabilidade e violência. É uma relação que teria que ser estabelecida não em alguns meses, mas estendida durante um período maior de tempo.

Ainda seguindo o pensamento de que a ação dessas agências vai ser focada em uma dupla ação, tanto no alívio para a população como na reaproximação do Estado da realidade local, e não em uma ação ostensiva de prover todos os atributos necessários para seu desenvolvimento, é possível afirmar que o sofrimento na violência urbana demande uma intervenção que vise à atenuar a situação do local (Bangerter, 2010; Duijsens, 2010). O que irá mudar não é a motivação inicial da ação, mas o modo pelo qual esta será feita. Não será uma medida paliativa e situacional, mas um conjunto de medidas que dê a resiliência necessária para tentar deflagrar a relação direta entre a vulnerabilidade local e a violência.

A presença da organização seria voltada para o reestabelecimento normal da situação o mais rápido possível. Tendo em vista que nos casos em que os Estados não apresentam condições de falência absoluta o objetivo da ação seria de aproximar a 
relação entre esse Estado e a população local. A presença das agências visa intervir no ciclo vicioso da vulnerabilidade e não no controle estatal sobre a população e território local. É uma medida focada na eliminação da vulnerabilidade a fim de que os fatores de risco não sejam capazes de se proliferar.

Tendo analisado a importância dos fatores de risco e da vulnerabilidade na estruturação da violência urbana e ilustrado como as agências humanitárias podem servir como mediadores entre Estado e agentes da violência para intervir na edificação da tríade pobreza-violência-vulnerabilidade, faz-se necessário ilustrar esse estudo a partir de um caso, e observar como essa nova posição das agências humanitárias se dá. Para tanto, o caso das operações da Cruz Vermelha no México serve para verificar essas possibilidades.

\section{Ação da Cruz Vermelha no México: Operando para o fortalecimento da resiliência}

Tendo visto algumas considerações para analisar a ação humanitária dentro do ambiente de violência urbana como uma saída viável para o fortalecimento da resiliência local, é importante analisar em que medida essa operação já acontece e de que forma ela transcorre. Sendo assim, visando entender a ajuda humanitária como uma forma de provisão de resiliência mediante o combate da vulnerabilidade e atenuação dos fatores de risco, o caso Mexicano aparece como sendo relevante para a análise.

O estudo será focado no norte do país, uma área com altos índices de violência devido aos conflitos entre gangues de cartéis de drogas pelo controle das operações e territórios. Os indicadores de violência e homicídio aferidos em 2012 pela ONG Seguridad Justicia y Paz do México (Fig.1) nos dão a dimensão de como a região é afetada por esse fenômeno. Das 10 cidades mais violentas da América Latina aferidas por este relatório, 5 são mexicanas, sendo 4 destas na região norte do país. Juarez, a segunda cidade mais violenta no mundo, tem a ordem de 144,77 homicídios a cada 100 mil habitantes; em Torreón, 87,75; em Chihuahua e 82,96; e em Durango 79,88, sendo estas, respectivamente, as $7^{\mathrm{a}}, 8^{\mathrm{a}}$ e $9^{\mathrm{a}}$ cidades mais violentas da América Latina. Essa diferença reforça que a questão da violência no norte do México é um fenômeno que se circunscreve a essa localidade com maior influência do que em outros lugares do país. Esse ponto é fundamental para compreensão de que os fatores de risco e a 
vulnerabilidade local da região apresentam fatores peculiares e que precisam ser combatidos de modo específico, como será visto a frente.

Figura 1. Número de homicídios a cada 100 mil habitantes (Seguridad Justicia y Paz do México, 2012)

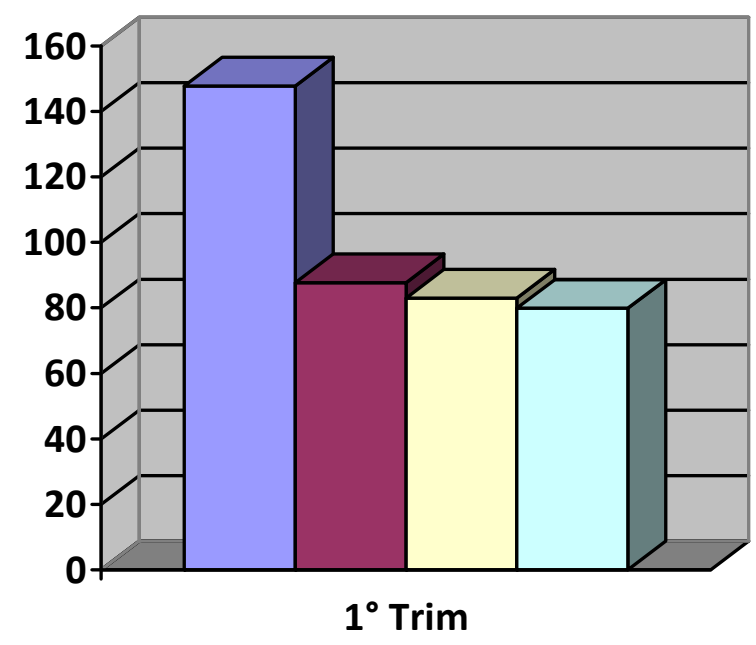

\begin{tabular}{|l|}
\hline \\
Juarez (2a cidade \\
mais violenta do \\
mundo) \\
$\square$ Torreón ( 7ạ cidade \\
mais violenta do \\
mundo) \\
$\square$ Chiahuahua (8a \\
cidade mais \\
violenta do mundo) \\
$\square$ Durango (9ạ cidade \\
mais violenta do \\
mundo) \\
\hline
\end{tabular}

Nesse caso, o ambiente de pobreza, aliado aos fatores de risco das localidades encontram na vulnerabilidade um potente catalisador da violência, deixando a situação em grave estado, necessitando de combate efetivo a essa violência. Outro ponto importante é que o Estado mexicano é, de facto, soberano da maior parte de seu território, tendo na região norte os problemas de controle - tanto físico quanto político -, o que também configura o ambiente em que o vislumbre de ter uma agência humanitária como provedor de resiliência contra a vulnerabilidade é possível. Não há uma perda completa de controle do território nacional, mas apenas parcial da região norte, na qual o Estado mexicano encontra impossibilidades de ação e forte resistência na localidade, principalmente após as medidas de ataque ofensivo ao combate do narcotráfico estabelecido pelo Presidente Felipe Calderón no ano de 2007 (Gootemberg, 2010).

A militarização do conflito a partir da ação ostensiva de Calderón fez com que uma situação de violência extrema se estabelecesse na região, com operações militares de larga escala para tentar desmobilizar esses cartéis. Em meio ao fogo cruzado, a população local vê-se em um ambiente de guerra declarado, no qual o elevado número de mortes - em torno de 26 mil de 2007 a 2010 - é reflexo da situação caótica em que o local vive (Gootemberg, 2010; Paley, 2011). 
A operação da Cruz Vermelha na localidade se dá pela Sociedade Nacional do México e pela Delegação Regional do Comitê Internacional da Cruz Vermelha. A Delegação do México do Comitê Internacional da Cruz Vermelha foi criada em 1998 para dar suporte aos migrantes que tentam atravessar a fronteira com os Estados Unidos e a suas famílias (CICV, 2011a). É interessante observar que o caráter inicial da Delegação visava o migrante e a fronteira dos Estados Unidos, problema que era mais latente, mas que também pode ser inserido dentro do reflexo da pobreza. O CICV pretendia, então, dar apoio para as famílias quando o indivíduo em questão morre e tentava estruturar uma política de procedimentos forenses para a identificação de corpos que ficam pelo deserto. Em 2002, a Delegação ganhou um caráter regional, passando a incluir em sua área de influência a Costa Rica, Cuba, El Salvador, Guatemala, Honduras, Nicarágua e o Panamá (CICV, 2011a; Delegação Regional do México, 2010).

Essa medida possibilitou que as sociedades nacionais tivessem uma coesão de esforços a fim de cumprir com os seus objetivos. O escopo da ação da Delegação Regional continuava a ser na ajuda a migrantes e famílias de pessoas desaparecidas, porém tinha também a missão de monitoramento de detentos, prevenção de violência entre jovens e suporte às Sociedades Nacionais.

Existe um projeto de cooperação entre o Comitê Internacional da Cruz Vermelha e a Cruz Vermelha do México para prover esse tipo de ajuda na fronteira com os Estados Unidos, não se restringindo aos indivíduos em si (CICV, 2011a). Há um esforço especial para os amputados nessa travessia, com uma cooperação para atenuar seu sofrimento (CICV, 2011). A ação de ajuda às populações inseridas dentro do conflito surge em um segundo momento, com o foco no trabalho com os afetados pelos cartéis de drogas no norte do México, bem como o ensino e treinamento de normas do direito internacional humanitário para o exército combatente para evitar e prevenir abusos de Direitos Humanos (Delegação Regional do México, 2010).

É por meio das operações e do intuito inicial das ações da Delegação do México do Comitê Internacional da Cruz Vermelha e de uma breve análise das localidades afetadas que podemos compreender quais seriam os fatores de risco em "nexo 
primário”7 . Conforme Agostini et al (2007) ressaltam é fundamental, portanto, a análise do ambiente urbano a fim de estabelecer a relação entre fatores de risco e o processo que leva a formação da violência. Começa-se o processo com a identificação das causas primárias, que são vistas criando um contexto específico de fatores de risco. A interação entre esses fatores é que resultam em atos violentos, catalisados pela vulnerabilidade.

Compreendendo essa noção de nexo primário e a tradução de um alinhamento comum de questões que são perpassadas pelas localidades, podemos assim começar a estabelecer um panorama dos fatores de risco da localidade. O primeiro ponto a ser levantado pode ser fixado como a cauda da preocupação inicial com a migração para os Estados Unidos: a falta de oportunidade econômica no local aliada ao ambiente violento. Além da proximidade geográfica com os Estados Unidos, o que torna o norte do México um destino natural para aqueles que tentam atravessar a fronteira, a economia local apresenta poucas oportunidades dentro de mercados legalizados e fora do ciclo da violência promovida pelos cartéis (Paley, 2011). Dado o controle ostensivo dessa região pelas gangues, a economia também circula dentro desses termos, o que circunscreve ainda mais a situação da pobreza dentro da situação da violência generalizada (Gootemberg, 2010; Saltillo, 2011).

A noção de uma economia direcionada para o ciclo de violência apresenta um ponto relevante: a inclusão da lógica de uma “economia da violência” que move o local. Essa cultura de manutenção de atividades ilícitas na fronteira e da estruturação de uma rede de cartéis e gangues na região tem seu início nos anos 70 e perpassa todos os anos 80. Com a pressão aplicada aos cartéis de Medelín, na Colômbia, houve um redirecionamento da possibilidade dos fluxos de cocaína e meta-anfetamina para as cidades do norte do México, que, facilitadas pela proximidade geográfica, apresentavam um pólo natural de atração dessas atividades. Sendo assim, a estruturação dessa relação entre o reduto nas cidades do norte - notadamente em Sinaloa e Juarez - e uma economia da violência aparece como um fator de risco primário ao desencadeamento da violência (Paley, 2011).

Não obstante, as subsequentes crises de 2008 e 2010 afetaram em o país como um todo, tendo o crescimento do PIB per capita chegado a 0,6\% ao ano (Saltillo, 2011), um

\footnotetext{
${ }^{7}$ Novamente, o Trabalho de Agostini, G.; Chianese, F.; French, W.; Sandhu, A. Understanding the Processes of Urban Violence: An Analytical Framework aparece como fundamental dentro do presente trabalho. Pra mais informações sobre a contribuição relacional dos nexos, ver páginas 25-31
} 
dos menores do mundo. Esse cenário recente de estagnação pode ser encarado como um contexto fundamental para o aumento da violência - em quantidade e em impacto -, uma vez que fortalece o fator de risco de desigualdade econômica e aumenta a vulnerabilidade. A configuração de um estado de crise econômica pode ser encarada como um fator de risco de nexo primário uma vez que a situação caminha para um estado de permanente desconfiança quanto às políticas orientadas pelo governo (Gootemberg, 2010).

Outro ponto importante da análise é perceber como as economias da ilegalidade estão conectadas com uma dependência estratégica dos Estados Unidos. A proximidade com os EUA também acaba por incorporar não só a economia da ilegalidade, mas também a própria economia local "legal” que fica vinculada a um sistema de exportação direto para os EUA. A crise econômica americana teve seu reflexo ainda mais acentuado devido a essa relação intrínseca de dependência da localidade (Saltillo, 2011).

Aliado a essa noção da falta de oportunidades locais e de uma queda no crescimento e bem-estar, a percepção de uma crise na localidade com a banalização da violência e do medo pelas gangues é outro ponto fundamental. A importância de considerar a relação com as gangues dentro de um cenário como esse se torna vital, uma vez que a administração tanto da economia como do viver social perpassa pelas relações e noções de poder que esses indivíduos tem. O trabalho de Oliver Bangerter (2010) apresenta-se como uma referência no campo de estudos sobre ajuda humanitária. O autor aborda a questão das organizações humanitárias dentro do cenário urbano, focando na capacidade das agências humanitárias interferirem a longo-prazo a fim de realizar um projeto mais estrutural, corroborando com a visão de uma ação que objetive a criação da confiança entre os membros do conflito. Seu trabalho foca a questão das gangues territoriais e seu impacto para os atores humanitários e tem como objetivo compreender como se dá a ação das gangues territoriais ${ }^{8}$.

O debate sobre a interferência das organizações humanitárias tem como ponto de partida o questionamento da ação dos agentes humanitários. O autor afirma que os conflitos urbanos não são tradicionalmente um lugar em que as agências humanitárias

\footnotetext{
${ }^{8}$ Bangerter (2010) afirma que a definição de "gangues” é nebulosa, e é mais importante compreendê-las por sua ação do que definir sua essência, a fim de que seja possível o desenvolvimento de uma estratégia a ser perseguida pelo agente humanitário.
} 
internacionais são previstas a estarem em ação, mas que, todavia, realizam seu trabalho sem ter a sua legitimidade posta em questão. Ao comentar que essas agências necessitam a verificação das reais necessidades a fim de administrar as suas atividades, Bangerter identifica nessa ação um caráter de maior prazo do que o habitual. Os requisitos para tratar com as gangues, foco do seu artigo, não poderiam ser periféricos e sim de longo prazo uma vez que demandam uma relação de mediação e confiança.

Para tanto, não seria possível qualquer agência ser a responsável por essa tarefa, sendo só capazes organizações grandes e com um staff capaz. Bagerter sugere a Cruz Vermelha como tal agente, não sendo a única, mas uma das possíveis. Os fatores preponderantes dessa escolha são, em larga medida: (1) o grande e qualificado efetivo da organização, contando com profissionais de diversas áreas do saber e em diversas localidades, o que facilitaria também a inclusão de pessoal local para fortalecer os laços de confiança; e (2) a maior capacidade de engendrar projetos de longo prazo, estruturados na alta complexidade organizacional do CICV, que poderia fornecer o suporte necessário para essa relação (Bangerter, 2010).

A partir da compreensão desses três fatores de risco primários, a análise dirige-se para as considerações de como, efetivamente, a ação da Cruz Vermelha dentro do México pode interferir nesse ciclo de vulnerabilidade, pobreza e violência. É importante ressaltar que essas medidas apontam mais para uma diretriz que visa à quebra de estrutura, como de fato ações concretas que tenham, deliberadamente, em seu escopo de ação ou em seu plano de metas a atenuação da vulnerabilidade. Elas acabam contribuindo para tal propósito ao servir de pólo exterior à situação, oferecendo uma estrutura que incentiva, principalmente, a construção da resiliência mediante a retirada da influência de todo o ambiente de violência que acaba se estruturando como o modo de operação da localidade.

As ações terão um foco que serve a um duplo propósito dentro dessa preocupação com a desarticulação da estrutura permissiva à vulnerabilidade, considerando fundamentalmente o princípio norteador básico da neutralidade. Essas medidas atentam para ambos os lados: a população, fortalecendo-a a partir da resiliência; e das gangues, mediante o incentivo à desmobilização. O objetivo central da ação é o fortalecimento dos indivíduos contra violência imposta para que se alivie o sofrimento e que se rompa esse processo retroalimentado de um contexto vulnerável e ambiente violento. No que 
tange ao Estado, as ações servem como uma medida para aproximá-lo da realidade, trabalhando não para o Estado ou com o Estado, mas como um consultor de práticas e ações para a retomada de ações na localidade (Coaffee, 2006; Agostini, Chianese, et al., 2007). Entender a bivalência desse tipo de ação é essencial, uma vez que interpor-se de modo neutro ajuda na função de servir como pólo exterior à situação.

Essa percepção da agência humanitária como um consultor exercendo um trabalho neutro reforça o argumento de mediação e confiança no longo prazo, fundamental para desestruturação das gangues e da violência estruturada mencionadas por Bangerter. Esse tipo de ação difere de uma ação de cunho desenvolvimentista, visando a edificar estruturas novas na sociedade em um processo de estabelecimento de metas, ou de uma ação substitutiva do Estado, ocupando as funções dentro do “vácuo de poder”. A ação é centrada no alívio do sofrimento com medidas que visem à atenuação da vulnerabilidade a fim de romper um ciclo que se retroalimenta. O caráter temporal, entretanto, visando à ação com esse fim específico, não pode ser breve, mas considerar a construção de uma relação e assegurar a interação do Estado dentro da realidade do local. É uma ação que propõe uma lógica entre a ação apenas de relief humanitário a prática desenvolvimentista (CICV, 2011a; Bangerter, 2010).

Compreendido esse ponto, passemos de fato às ações da Cruz Vermelha dentro do México que inspiram esse pensamento. Elas podem ser analisadas em duas frentes. A primeira tange o contato, monitoramento e ajuda a migrantes, suas famílias e famílias de desaparecidos na travessia da fronteira México-Estados Unidos. Conforme dito anteriormente, a preocupação com os migrantes era a motivação da instauração da Delegação do México em 1998 e, desde então, tais indivíduos são um ponto focal nas operações da agência (CICV, 2011; CICV, 2011a).

Em 2010, a Delegação Regional assistiu mais de 2300 imigrantes. O trabalho é de caráter amplo, compreendendo desde curativos e bandagens a pré-natal nas mulheres grávidas encontradas nessa situação. Outro ponto importante da ação do CICV, em conjunto com a Sociedade Nacional Mexicana, é na atenção aos amputados no processo de travessia e em sua reabilitação nos centros instalados pelo Comitê Internacional. Segundo o relatório oficial de 2010 da Delegação, 36 pessoas receberam esse tipo de suporte nos quatro centros instalados para essa finalidade (Delegação Regional do México, 2010). A instalação de centros para o tratamento de feridos, amputados e para o 
atendimento das famílias dos migrantes em geral mostra de forma bastante clara a ação focada no alívio do sofrimento. Dado o abandono dos locais pela ação estatal, as tentativas de retomada pela força das localidades e a ocupação dessas cidades pelas gangues, a Delegação Regional da Cruz Vermelha é tida como um ente neutro nessa dualidade.

A sua operação irrestrita visa a suprir essa necessidade não atendida, dando resiliência no que consiste na melhora da capacidade do indivíduo de viver naquela situação, ao mesmo tempo em que realiza ações que tentam conscientizar o Estado e seu aparato para a situação. Aliado ao hospital, outra preocupação que demonstra essa tônica é a convenção idealizada pela Delegação Regional para criar um protocolo e medidas de identificação de indigentes na travessia do deserto em direção aos EUA. A aproximação do Estado dessa realidade aparece como uma medida fundamental para quebrar o contexto vulnerável que catalisa a ação dos fatores de risco, relação fundamental para a compreensão da necessidade desse tipo de ação (Delegação Regional do México, 2010).

Essas diversas medidas de atendimento aos indivíduos em situação vulnerável respondem pela provisão de serviços essenciais que não são oferecidos pelo governo, uma vez que este apresenta dificuldade de inserção dentro da localidade dado a construção dessa estrutura assentada em uma economia e modo de vida violentos. É importante atentar que, de forma alguma, essas medidas, em grande parte superficiais, serão suficientes para estacar a dinâmica do ciclo de violência, pobreza e vulnerabilidade. Elas servem para prover o elemento da resiliência na população, funcionando como um pólo que possibilita a reestruturação nas dinâmicas da população. Essa atitude, aliada à ação do Estado de reaproximação - encaminhada por essa recondução de estruturas - é que podem se mostrar como eficientes dentro de um complexo multifacetado da violência estrutural.

A segunda vertente tange de forma mais específica à questão da violência no norte do país, a qual aparece como um fator preocupante tanto para a prática da organização como a segurança do próprio staff. Os relatos das operações e da vida nessas cidades, como os relatos de médicos que estão in loco na área de Juarez, retratam um cenário de completo domínio das gangues. Elas controlam quase todos os aspectos da vida pública, chegando a exercer uma espécie de poder de polícia, controlando quem entra e quem sai 
das cidades. Os médicos que trabalham nos hospitais comentam que o trabalho está em uma fase bastante delicada, na qual os membros das gangues passaram a invadir armados locais como hospitais e estão matando alvos marcados dentro desses locais, ou estabelecendo a prática constante de sequestros de pacientes e até de médicos vinculados ao CICV e ao Comitê Nacional do México (Delegação Regional do México, 2010; CICV, 2011a).

A situação apresenta uma dificuldade à assistência dada às vítimas do conflito, priorizando o atendimento de feridos, mas com a preocupação na questão estrutural da violência. Atentos à questão do constante abuso de direitos humanos na região, tanto por parte das gangues como por parte do Governo e suas operações de combate militarizado contra o tráfico, o CICV, associado com o Governo e com a Sociedade Nacional do México, está fortalecendo os laços do Direito Internacional Humanitário (DIH) na região. Tangendo essa segunda vertente das ações da delegação regional, houve, portanto, dois esforços de estabelecer um protocolo de respeito ao DIH por parte do CICV: um primeiro em parceria com o Ministério de Relações Exteriores do México para realizar uma conferência sobre o DIH e discutir as doutrinas na região na América Latina e Caribe, em especial na região norte do México. Um segundo esforço foi um acordo com a marinha mexicana, em colaboração com o Ministério da Defesa, para que as operações do Exército e da Força Aérea levem em consideração o DIH (Delegação Regional do México, 2010). Essas medidas vão ao encontro da percepção da agência humanitária como um agente neutro que vai colaborar tanto com o Estado quanto com as outras partes do conflito. As ações de garantia dos Direitos Humanos Internacionais são exemplo de que a reaproximação do Estado tem que ser feita de modo a desestruturar o conteúdo fundamental da violência na localidade, atentando para o respeito a essas garantias.

Essas medidas apresentam um passo muito importante na concepção de um CICV que atua em função de desestruturar o contexto de vulnerabilidade, fortalecer a resiliência local e na atenuação dos fatores de risco. A percepção da necessidade do alívio do sofrimento, as ações médicas na área, os incentivos de aproximação do Estado mexicano da realidade dos DIH na localidade, a relação de confiança em longo prazo que está tentando ser estabelecida, são exemplos de como as operações da Delegação Regional no México estão contribuindo para a desvinculação de fatores de risco na 
Região - como a percepção de uma crise na localidade com a banalização da violência e do medo pelas gangues (Bangerter, 2010). A política adotada agora é a conscientização de que o uso de força excessiva na região nem sempre é a melhor alternativa para a contenção desses grupos. A linha de ação, segundo o relatório de 2010, no México tem estreitado os laços entre forças armadas das gangues e de segurança nacional para criar uma política de estabilidade na região. Além disso, como de costume, o CICV realiza visitas constantes aos presos acusados de participar dessas gangues para verificar se ocorre algum abuso (Delegação Regional do México, 2010).

O resultado dessas ações ainda é bastante incipiente, dado a recente análise que está sendo feita sobre a própria situação e seus indicadores. Porém, o que é possível inferir como fundamental nessa análise é a importância de se ter as agências humanitárias como um pólo exterior, que pode interferir na situação como articulador de diversas medidas que ambicionam a desestruturação da violência e a atenuação da vulnerabilidade por meio da provisão de resiliência, aparecendo de forma concreta na construção e manutenção de estruturas de necessidades básicas primárias - como saúde -, além do acompanhamento e reaproximação das operações do Estado, servindo como um suporte técnico e administrativo. A operação no México aparece, portanto, como o início da concretização efetiva dessa nova postura das agências humanitárias, porém, para avaliar a efetividade absoluta dessas medidas, um acompanhamento futuro terá de ser feito.

\section{Conclusão}

Sendo assim, é importante fazer um apanhado da situação no México e da observação de uma operação atenta na questão da desestruturação do ciclo de pobreza, vulnerabilidade e violência. O ponto a ser observado é o objetivo da ação, voltado para acabar com o contexto de vulnerabilidade que catalisa os fatores de risco, que em sua interação levam a estruturação da violência. Essa percepção, sem um fator único, mas como uma associação de fatores em conjunção a um contexto apresenta uma visão importante para lidar com os diversos aspectos de manifestação da violência. Oferecendo o alívio do sofrimento por ações focadas no bem-estar e na preocupação da exacerbação da violência, as operações tem a intenção primeira de desarticular essa 
estrutura multifacetada do ciclo, interferindo no contexto e atenuando os fatores de risco, evitando o atrito e a catálise do processo de violência.

Os resultados disso, em longo prazo, tendem à estabilização desse pano de fundo, no qual os fatores de risco, por mais que ainda existentes, não terão força na sua interação para estruturar a violência ou não encontraram um ambiente vulnerável suficiente a eles. É uma ação multifacetada e com um mecanismo mais sofisticado de ação do que uma medida desenvolvimentista - que visa só a questão da pobreza dentro do ciclo e de uma violência pela falta de oportunidade - ou intervencionista - que visa só a questão da violência pela violência. Pela desestruturação desse ciclo atenuando os fatores de risco que alocam a violência, contribuindo para fortalecer a população mediante o fortalecimento da resiliência e, por conseguinte, o enfraquecimento das vulnerabilidades, a ação que leva em consideração essa co-constituição entre esses três fatores acaba por abarcar mais elementos que dão gênese a uma situação de violência extremada. É importante frisar que a ação do Estado é fundamental em corresponder com as iniciativas da agência humanitária com medidas de reaproximação e incentivo econômico na área, uma vez que não é nem responsabilidade e nem da capacidade das agências lidar com esse aspecto.

Em suma, tendo em vista a Delegação Regional do México, a ação das agências humanitárias ajudam no combate da vulnerabilidade e na atenuação de fatores de risco parece uma alternativa para o fortalecimento da resiliência da população local e da desestruturação do ciclo de pobreza, vulnerabilidade e violência. 


\section{Referências}

AGOSTINI, et al. Understanding the Processes of Urban Violence: An Analytical Framework. London School of Economics. Londres, p. 70. 2007.

BANGERTER, O. Territorial gangs and their consequences for humanitarian players. International Review of the Red Cross, v. 92, n. 872, p. 387-406, Junho 2010.

BARAKAT, S.; DELY, S.; ZYCK, S. A. perspective., 'A tradition of forgetting': stabilisation and humanitarian action in historical perspective. Overseas Development Institute, 2010. 1-23.

CARILLO, A. C. Internal displacement in Colombia: humanitarian, economic and social consequences in urban settings and current challenges. International Review of the Red Cross, v. 91, n. 875, p. 527-546, Setembro 2009.

CICV. Mexico: a touch of humanity in the face of adversity, 2011. Disponivel em: $<$ http://www.icrc.org/eng/resources/documents/feature/2011/mexico-feature-2011-0530.htm>. Acesso em: 14 Setembro 2011.

a. The ICRC regional delegation in Mexico, 01 Junho 2011a. Disponivel em: $<$ http://www.icrc.org/eng/where-we-work/americas/mexico/overview-mexico.htm>. Acesso em: 14 Setembro 2011.

COAFFEE, J. From Counterterrorism to Resilience. The European Legacy, v. 11, n. 4, p. 389-403, 2006.

DELEGAÇÃO REGIONAL DO MÉXICO. ICRC Annual Report. ICRC. Cidade do México, p. 1-6. 2010.

DUIJSENS, R. Humanitarian Challenges of Urbanization. International Revier of Red Cross, v. 92 , n. 878, p. 351-368, Junho 2010.

GOOTEMBERG, P. Blowback: The Mexican Drug Crises. NACLA Report on the Americas, p. 1-12, Novembro/Dezembro 2010.

HARROFF-TAVEL, M. Violence and humanitarian action in urban areas: new challenges, new approaches. International Review of the Red Cross, v. 92 , n. 878, p. 329-350, Junho 2010. 
MUGGAH, R. Stabilising Fragile States and the Humanitarian Space. In: BERDAL, M.; ACHIM, W. Ending Wars, Consolidating Peace: Economic Perspectives. 1. ed. [S.l.]: Routledge, 2010. Cap. 2, p. 258.

OMS, O. M. D. S. World Report on Violence and Health. Organização Mundial da Saúde. Genebra, p. 45. 2010.PALEY, D. Off the Map in Mexico. The Nation, Tamaulipas, p. 20-24, Maio 2011.

SALTILLO. Making the desert bloom. The Economist, v. 400, n. 8748, p. 1-4, Agosto 2011.

SEGURIDADAD, JUSTICIA Y PAZ. Las 50 ciudades más violentas de la Latinoamérica. Disponível em: <

http://www.seguridadjusticiaypaz.org.mx/biblioteca/finish/5/145/0>. Acesso em $27 / 08 / 2012$

URCV. BACKGROUND. Urban Resilience in Situations of Chronic Violence, 2011. Disponivel em: <http://www.urbanresilience.org/background.html>. Acesso em: 28 out. 2011. 